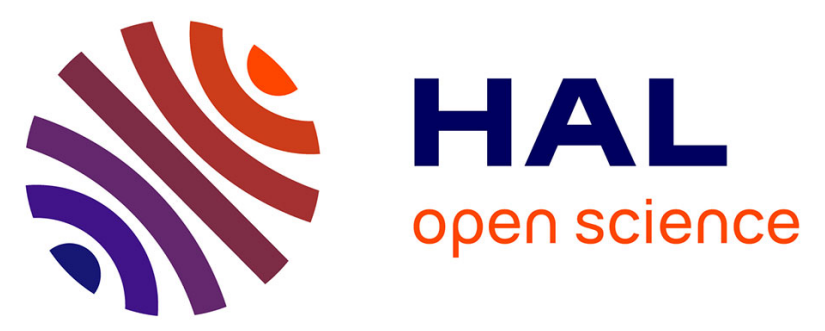

\title{
Distributed photovoltaic architecture powering a DC bus: Impact of duty cycle and load variations on the efficiency of the generator
}

Hadj Allouache, Abdallah Zegaoui, Mohamed Boutoubat, Aicha Aissa

Bokhtache, Fatma Zohra Kessaissia, Jean-Pierre Charles, Michel Aillerie

\section{To cite this version:}

Hadj Allouache, Abdallah Zegaoui, Mohamed Boutoubat, Aicha Aissa Bokhtache, Fatma Zohra Kessaissia, et al.. Distributed photovoltaic architecture powering a DC bus: Impact of duty cycle and load variations on the efficiency of the generator. TMREES18-Spring Meeting "Technologies and Materials for Renewable Energy, Environment and Sustainability", Feb 2018, Beirut, Lebanon. pp.30006 - 30006, 10.1063/1.5039193. hal-01802892

\section{HAL Id: hal-01802892}

https://hal-centralesupelec.archives-ouvertes.fr/hal-01802892

Submitted on 29 May 2018

HAL is a multi-disciplinary open access archive for the deposit and dissemination of scientific research documents, whether they are published or not. The documents may come from teaching and research institutions in France or abroad, or from public or private research centers.
L'archive ouverte pluridisciplinaire $\mathbf{H A L}$, est destinée au dépôt et à la diffusion de documents scientifiques de niveau recherche, publiés ou non, émanant des établissements d'enseignement et de recherche français ou étrangers, des laboratoires publics ou privés. 
Distributed photovoltaic architecture powering a DC bus: Impact of duty cycle and load variations on the efficiency of the generator

Hadj Allouache, Abdallah Zegaoui, Mohamed Boutoubat, Aicha Aissa Bokhtache, Fatma Zohra Kessaissia, Jean-Pierre Charles, and Michel Aillerie

Citation: AIP Conference Proceedings 1968, 030006 (2018); doi: 10.1063/1.5039193

View online: https://doi.org/10.1063/1.5039193

View Table of Contents: http://aip.scitation.org/toc/apc/1968/1

Published by the American Institute of Physics 


\title{
Distributed Photovoltaic Architecture Powering a DC bus: Impact of Duty Cycle and Load Variations on the Efficiency of the Generator
}

\author{
Hadj Allouache ${ }^{1}$, Abdallah Zegaoui1 ${ }^{1,2,3, a)}$, Mohamed Boutoubat ${ }^{4, b)}$, \\ Aicha Aissa Bokhtache ${ }^{1}$, Fatma Zohra Kessaissia ${ }^{1}$, \\ Jean-Pierre Charles ${ }^{2,3}$, and Michel Aillerie ${ }^{2,3, c)}$ \\ ${ }^{1}$ LGEER Laboratory, Hassiba Benbouali University, BP151, 02000 Chlef, Algeria. \\ ${ }^{2}$ LMOPS, Université de Lorraine, EA-4423, 2 rue E. Belin, 57070 Metz, France \\ ${ }^{3}$ LMOPS, CentraleSupelec, 2 rue E. Belin, 57070 Metz, France \\ ${ }^{4}$ LACOSERE Laboratory, Laghouat University, Algeria. \\ ${ }^{\text {a)} C o r r e s p o n d i n g ~ a u t h o r: ~ a b d . z e g a o u i @ g m a i l . c o m ~}$ \\ b)boutoubat90@yahoo.fr \\ c)michel.aillerie@supelec.fr
}

\begin{abstract}
This paper focuses on a photovoltaic generator feeding a load via a boost converter in a distributed PV architecture. The principal target is the evaluation of the efficiency of a distributed photovoltaic architecture powering a direct current (DC) PV bus. This task is achieved by outlining an original way for tracking the Maximum Power Point (MPP) taking into account load variations and duty cycle on the electrical quantities of the boost converter and on the PV generator output apparent impedance. Thereafter, in a given sized PV system, we analyze the influence of the load variations on the behavior of the boost converter and we deduce the limits imposed by the load on the DC PV bus. The simultaneous influences of 1- the variation of the duty cycle of the boost converter and 2- the load power on the parameters of the various components of the photovoltaic chain and on the boost performances are clearly presented as deduced by simulation.
\end{abstract}

\section{INTRODUCTION}

The use of solar photovoltaic (PV) energy exponentially grows during the past decades. Two factors are encouraging the development of green energy. It concerns, 1- the countries energy policies that continue to subsidize its use and 2- the reduction of the greenhouse gases in order to fight against the pollution of the environment. Among other renewable energies, solar energy production increased to meet the needs of energy demand in power electricity, mainly by photovoltaic energy and in global warming, mainly by solar thermal energy [1,2]. Concerning the PV energy, the adaption of voltage to the various levels of voltage concerned by the transport or the distribution at a wide or local levels, requires the integration between the PV plan and the grid of DC/DC boost converters associated to inverters when an AC grid is concerned. In the PV converters, the maximum power that can be converted is assumed by a maximum power point tracker, MPPT, based on dedicated algorithms currently integrated in a controller driving the power switch of the boost. This MPPT generates the ON/OFF of the switches, related to their operation duty cycle, in order to reach the MPP under real environmental conditions [3-8]. For the transport of the PV energy with a high direct continuous voltage (HVDC) bus ranging between 100 to $1 \mathrm{kV}$, a special topology of boost converter is required between the PV generator and the HVDC bus [9-12]. For that purpose, several step-up converter architectures have been proposed in literature. In Refs. [13-15], a switched capacitor technique is chosen for high-gain conversion systems. To generate a high step-up voltage from photovoltaic sources, coupled inductor 
converter is widely discussed in Refs. [16-21]. Finally, in Refs. [22-25], the tapped inductor boost technique is developed and applied in several applications.

In the current contribution, we develop a new approach of MPPT that links the load powered by the boost to the apparent photovoltaic generator impedance. Thanks to simulation, we built a simple new adaptation impedance method by considering the apparent PV generator and the load impedances only. In the method, the influence of both the duty cycle and the load variations on the boost electrical quantities and the apparent impedance of PV generator are simulated.

\section{THE BASIC PV SYSTEM}

Figure 1 shows the basic PV system studied. In typical distributed architecture for PV production on a HVDC bus, this kind of system constitutes an autonomous block connected in parallel to the bus; in this case, the resistive load $R_{c h}$ is deported on the bus itself. This block is constituted by a photovoltaic generator (for actual practical simulation a module ESM 80s-125 was chosen [26]) and a boost converter. To minimize the ripples at the input ( $\mathrm{V}_{\mathrm{pv}}$ and $\left.\mathrm{I}_{\mathrm{pv}}\right)$, and at the output $\left(\mathrm{V}_{\mathrm{s}}\right.$ and $\left.\mathrm{I}_{\mathrm{s}}\right)$, the boost parameters, i.e. the inductance $(\mathrm{L})$ and capacities $\left(\mathrm{C}_{\mathrm{e}}, \mathrm{C}_{\mathrm{s}}\right)$ are rigorously calculated [7, 8], $\mathrm{R}_{\mathrm{L}}$ representing the internal resistance of the boost inductance. The output voltage is adjusted by varying the duty cycle by acting on the conduction time Tp of the boost. The MPPT algorithm ensures the duty cycle variation.

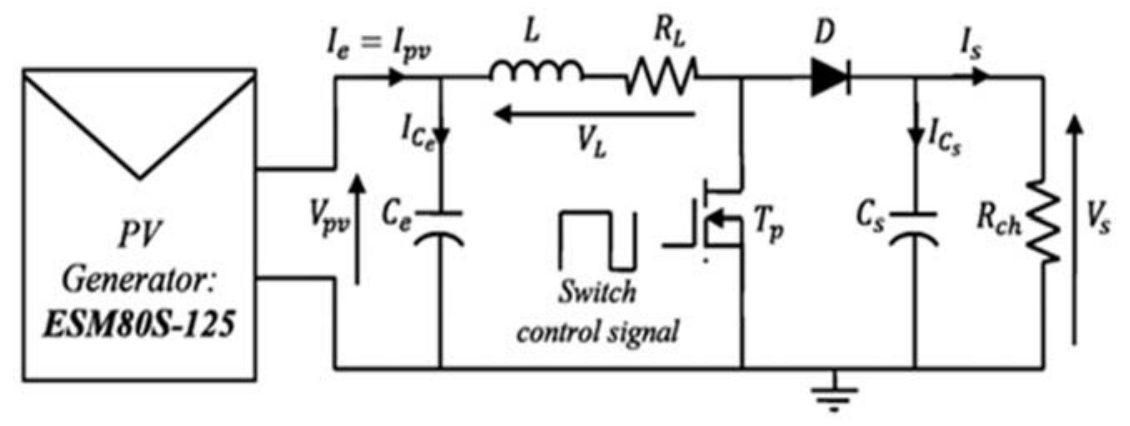

FIGURE 1. Layout of the studied system.

Considering the continuous conduction-operating mode of the boost, the necessary condition to assume that the average voltage provided at the inductance terminals is zero at steady state imposes the input voltage as an average voltage across the power switch [6], i.e.:

$$
\mathrm{V}_{\mathrm{s}}=\frac{1}{1-\alpha} \times \mathrm{V}_{\mathrm{pv}}
$$

where, $0 \leq \alpha \leq 1$ is the duty cycle of the switch control signal.

Moreover, assuming that the power exchanged between the photovoltaic generator (PVG) and the load is maintained (without boost loses), one can write:

$$
\mathrm{V}_{\mathrm{pv}} \times \mathrm{I}_{\mathrm{pv}}=\mathrm{V}_{\mathrm{s}} \times \mathrm{I}_{\mathrm{s}}
$$

The combination between equations (1) and (2), leads to the following relationship between the electric currents from the PV module and the load:

$$
\mathrm{I}_{\mathrm{s}}=(1-\alpha) \times \mathrm{I}_{\mathrm{pv}}
$$

When the boost is switched, during the period: $0<\mathrm{t}<\alpha \mathrm{T}$, one can express the input current ripples $\Delta \mathrm{I}_{\mathrm{L}}$ of the current $\mathrm{I}_{\mathrm{L}}$ in the inductance as:

$$
\Delta \mathrm{I}_{\mathrm{L}}=\alpha \frac{\mathrm{V}_{\mathrm{pv}}}{\mathrm{L} \times \mathrm{f}}
$$


where, $\mathrm{f}$ is the switching frequency. Then, the minimum value of the output necessary capacitor Cs, to assume a fixed ripple rate of the output voltage, is expressed as

$$
\mathrm{C}_{\mathrm{s}-\min }=\frac{\mathrm{I}_{\mathrm{s}}}{\Delta \mathrm{V}_{\mathrm{s}} \mathrm{f}} \alpha
$$

To enhance the output voltage, the output capacitor must verify:

$$
\mathrm{C}_{\mathrm{s}}>\frac{\mathrm{V}_{\mathrm{s}}}{\Delta \mathrm{V}_{\mathrm{s}} \mathrm{fR}} \alpha
$$

Since, an inductor opposes sudden changes in the current, the ripple $\Delta \mathrm{V}_{\mathrm{PV}}$ of the input voltage $\mathrm{V}_{\mathrm{PV}}$ is given by [11]:

$$
\Delta \mathrm{V}_{\mathrm{pv}}=\frac{1}{\mathrm{C}_{\mathrm{e}}}\left(\frac{1}{2} \times \frac{\mathrm{T}}{2} \times \frac{\Delta \mathrm{I}_{\mathrm{L}}}{2}\right)
$$

This Eq. 7 can be rewritten in the following form:

$$
\Delta \mathrm{V}_{\mathrm{pv}}=\frac{\alpha \mathrm{V}_{\mathrm{pv}}}{8 \mathrm{LC}_{\mathrm{e}} \mathrm{f}^{2}}
$$

So, to ensure a good input voltage ripple, the capacitor Ce must verify:

$$
\mathrm{C}_{\mathrm{e}}>\frac{\alpha}{8 \mathrm{Lf}^{2}} \times \frac{\mathrm{V}_{\mathrm{pv}}}{\Delta \mathrm{V}_{\mathrm{pv}}}
$$

\section{PROPOSED CRITERION FOR THE IMPEDANCE ADAPTATION}

In the continuous conduction mode $(\mathrm{CCM})$, the apparent resistance $\mathrm{R}_{\mathrm{pv}}$ that appears on the photovoltaic generator output is expressed by:

$$
\mathrm{R}_{\mathrm{pv}}=\frac{\mathrm{V}_{\mathrm{pv}}}{\mathrm{I}_{\mathrm{pv}}}=(1-\alpha)^{2} \mathrm{R}_{\mathrm{ch}}
$$

This last equation leads to the load resistance:

$$
\mathrm{R}_{\mathrm{ch}}=\frac{\mathrm{R}_{\mathrm{pv}}}{(1-\alpha)^{2}}
$$

Then, the expression of the duty cycle deduced of Eq. 11 becomes:

$$
\alpha=1-\sqrt{\frac{\mathrm{R}_{\mathrm{pv}}}{\mathrm{R}_{\mathrm{ch}}}}
$$

Since, the duty cycle $\alpha$ is always lower than unity and according to Eq. 12 one can conclude that the converter acts as a boost if the load resistor Rch verifies the following relation:

$$
\mathrm{R}_{\mathrm{ch}}>\mathrm{R}_{\mathrm{pv}}
$$

Besides, when the illumination varies from 100 to $1000 \mathrm{~W} / \mathrm{m}^{2}$ at a fixed temperature of $25{ }^{\circ} \mathrm{C}$, the optimum apparent resistance $\mathrm{R}_{\mathrm{opt}}$ of the commercial ESM80S-125 photovoltaic module varies from $51.56 \Omega$ to $3.78 \Omega$. Therefore, the load resistance $\mathrm{R}_{\mathrm{ch}}$ must be greater than $51.56 \Omega(3.78 \Omega)$ for the same illumination levels. According 
to Eqs. 12 and 13, we deduce that the impedance adaptation between the photovoltaic generator and the load must be done by acting on the value of the duty cycle $\alpha$. In fact, at optimal conditions and for a given $R_{\text {ch }}$, the apparent resistance of the photovoltaic generator becomes $R_{p v}=R_{o p t}$ and the duty cycle becomes $\alpha=\alpha_{\text {opt }}$. Finally, these two parameters will obey to Eq.12, thus becoming:

$$
\alpha_{\text {opt }}=1-\sqrt{\frac{\mathrm{R}_{\mathrm{opt}}}{\mathrm{R}_{\mathrm{ch}}}}
$$

Finally, Eq. 14 proves that the MPP position moves according to the resistance value of the load $\mathrm{R}_{\mathrm{ch}}$.

\section{The Maximum Admissible Load of the Generator}

As the solar PVG presents the minimum output impedance of the converter, it is necessary to estimate the maximum admissible load $\mathrm{R}_{\text {smax }}$. This minimum output impedance is achieved when the converter works with the maximum input power so with the maximum irradiation on the panel $(1000 \mathrm{~W} / \mathrm{m} 2)$ generating an electric current equal to its maximum, i.e. $4.55 \mathrm{~A}$ in our experiment (see the PVG ESM80S-125 datasheet). This electric current corresponds to a voltage equal to $17.6 \mathrm{~V}$ and a maximum power equal to $80 \mathrm{~W}$. Under these conditions, and in order to adapt this generator impedance to the maximum impedance of the load, the duty cycle value must be the largest possible achieving a value near $90 \%$. The output current $I_{s}$ and the output voltage $\mathrm{V}_{\mathrm{s}}$, when the boost operates at this value of duty cycle, are calculated as follows:

$$
\begin{aligned}
& I_{s}=\left(1-\alpha_{\max }\right) \times I_{\text {opt }_{1000 \mathrm{~W} / \mathrm{m}^{2}}}=(1-0.9120) \times 4.55=0.4004 \mathrm{~A} \\
& \mathrm{~V}_{\mathrm{s}}=\left(\frac{1}{1-\alpha_{\max }}\right) \times \mathrm{V}_{\mathrm{opt}_{1000 \mathrm{~W} / \mathrm{m}^{2}}}=\left(\frac{1}{1-0.9120}\right) \times 17.6=200 \mathrm{~V}
\end{aligned}
$$

Within this couple current-voltage, as defined by the Eqs. 15 and 16, the maximum load impedance $\mathrm{R}_{\text {smax }}$ is found equal to $500 \Omega$.

\section{The Minimum Admissible Load of the Generator}

Similarly to the calculation of the maximum admissible load presented in the previous section, the minimum admissible load $\mathrm{R}_{\text {smin }}$ can be calculated when the photovoltaic generator is at its maximum output impedance, which is achieved when irradiation is at a minimum level $(100 \mathrm{~W} / \mathrm{m} 2)$ generating an electric current at its minimum, i.e. 0.2663A in our experiments (see the PVG (ESM80S-125 datasheet). Therefore, this current level corresponds to a voltage equal to $13.7283 \mathrm{~V}$ given a power equal to $3.6552 \mathrm{~W}$. In order to adapt the output impedance of the generator impedance with the minimum load, the duty cycle value must be at its lowest value $(10 \%)$, which corresponds in the ideal case to the following output current $I_{s}$ and output voltage $V_{s}$, as follows:

$$
\begin{gathered}
I_{s}=\left(1-\alpha_{\min }\right) \times I_{o p t_{1000 / / m^{2}}}=(1-0.1) \times 0.2663=0.2397 A \\
\mathrm{~V}_{\mathrm{s}}=\left(\frac{1}{1-\alpha_{\min }}\right) \times \mathrm{V}_{\mathrm{opt}_{100 \mathrm{~W} / \mathrm{m}^{2}}}=\left(\frac{1}{1-0.1}\right) \times 13.7283=15.253 \mathrm{~V}
\end{gathered}
$$

Consequently, the minimum load impedance $\mathrm{R}_{\text {smin }}$ is found equal to $63.64 \Omega$.

Finally, as clearly described in Ref. [26], and to assume a correct driving of the generator, the MPPT algorithm represented by Eq. 14 imposes that the load resistance $R_{c h}$, remains located in the operation interval [ $\left.R_{\text {smin }}, R_{\text {smax }}\right]$.

\section{SIMULATION RESULTS}

Figure 2 shows the studied system circuit as implemented under Matlab/Simulink, considering the boost parameters as previously sized in Ref [26]. In order to reduce the simulation time, the boost is controlled by a pulse generator delivering a square wave of $10 \mathrm{kHz}$ at variable duty cycle. 


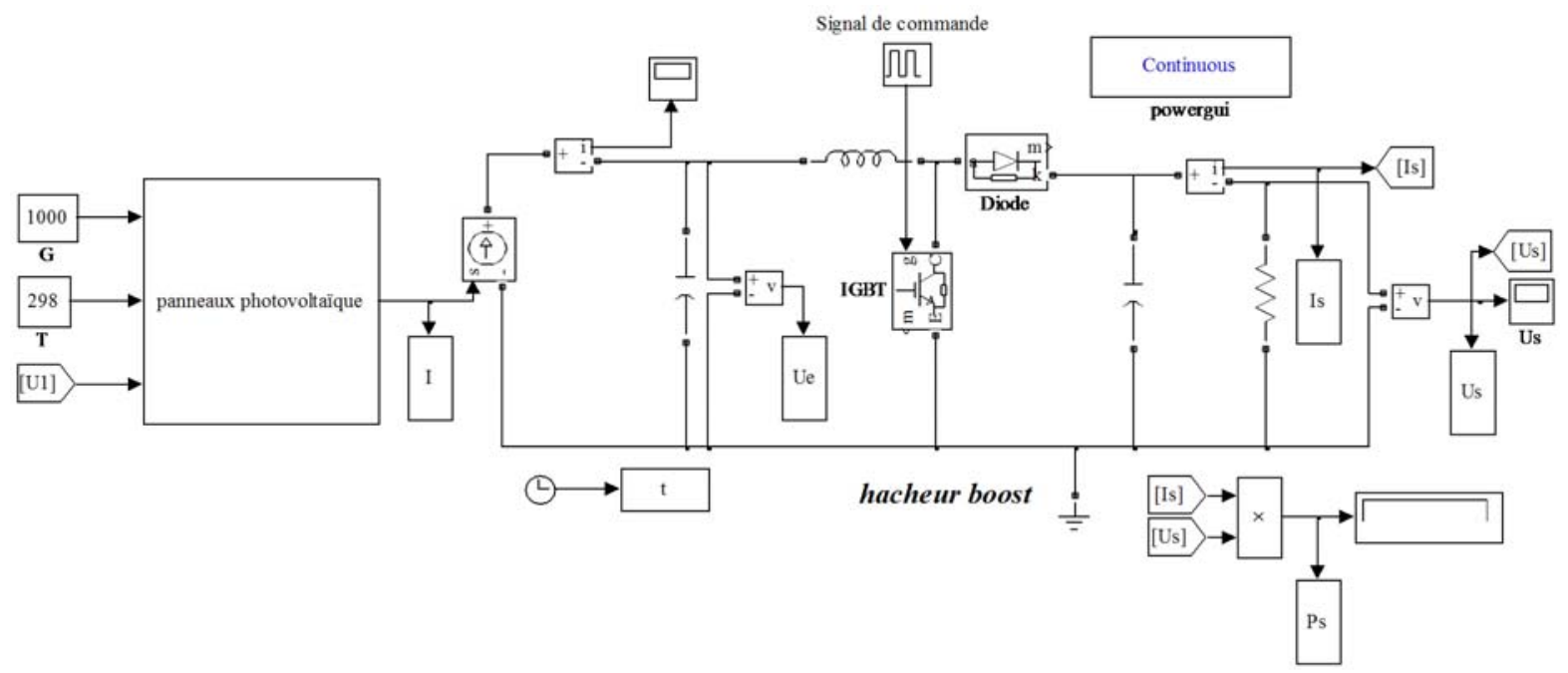

FIGURE 2. The studied system implemented under Matlab/Simulink software.

\section{The Maximum Power Point}

The above described adaptation impedance criterion is used to reach the MPP of the PVG.

For a fixed illumination level equal to $1000 \mathrm{~W} / \mathrm{m} 2$, at fixed ambient temperature equal to $25^{\circ} \mathrm{C}$, and a fixed load $\mathrm{R}_{\mathrm{ch}}=50 \Omega$. The optimum duty cycle is calculated according to Eq. 14 and its optimal value was found equal to $\alpha_{\mathrm{opt}}$ $=0.7250$. The obtained simulation results are shown in Figs. 3, 4, and 5 .
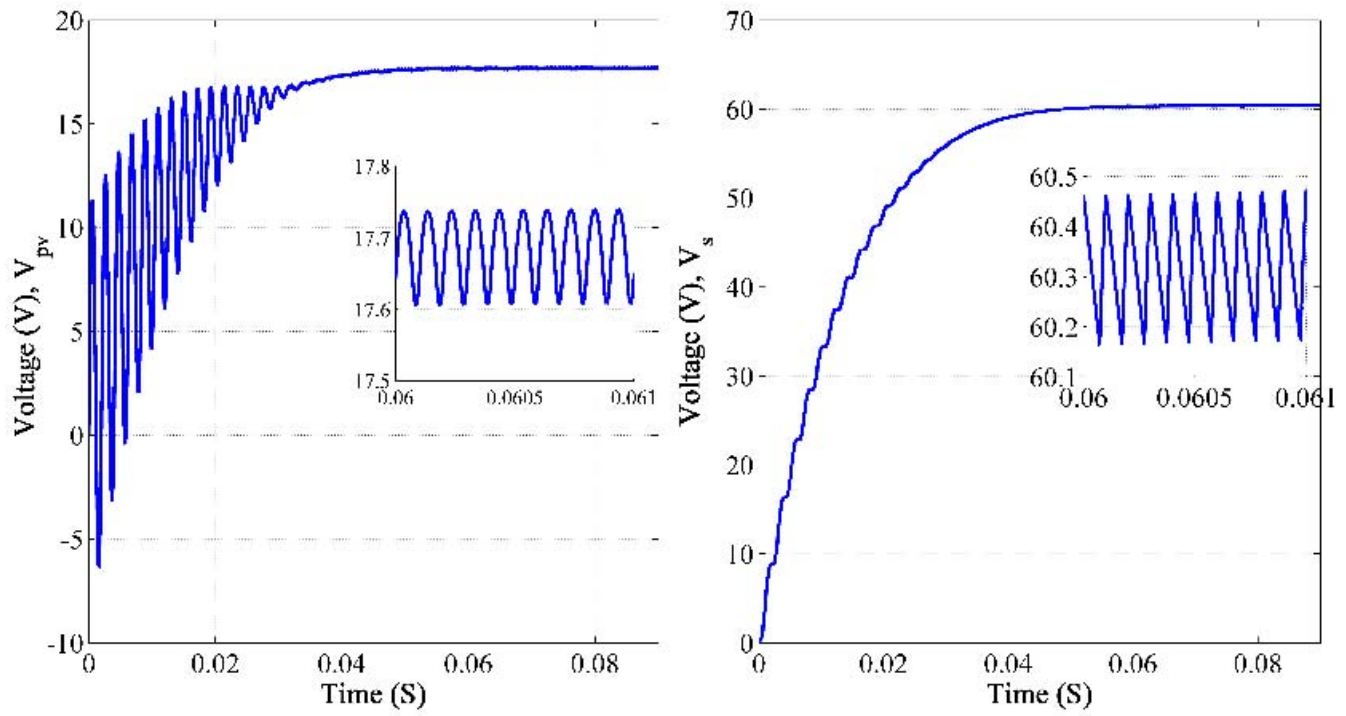

FIGURE 3. Input voltage, $V_{P V}$ and output voltage $V_{S}$ of the boost converter when $\alpha=0.7226, R_{c h}=50 \Omega$, irradiation $=1000$ $\mathrm{W} / \mathrm{m} 2$ at ambient temperature. 

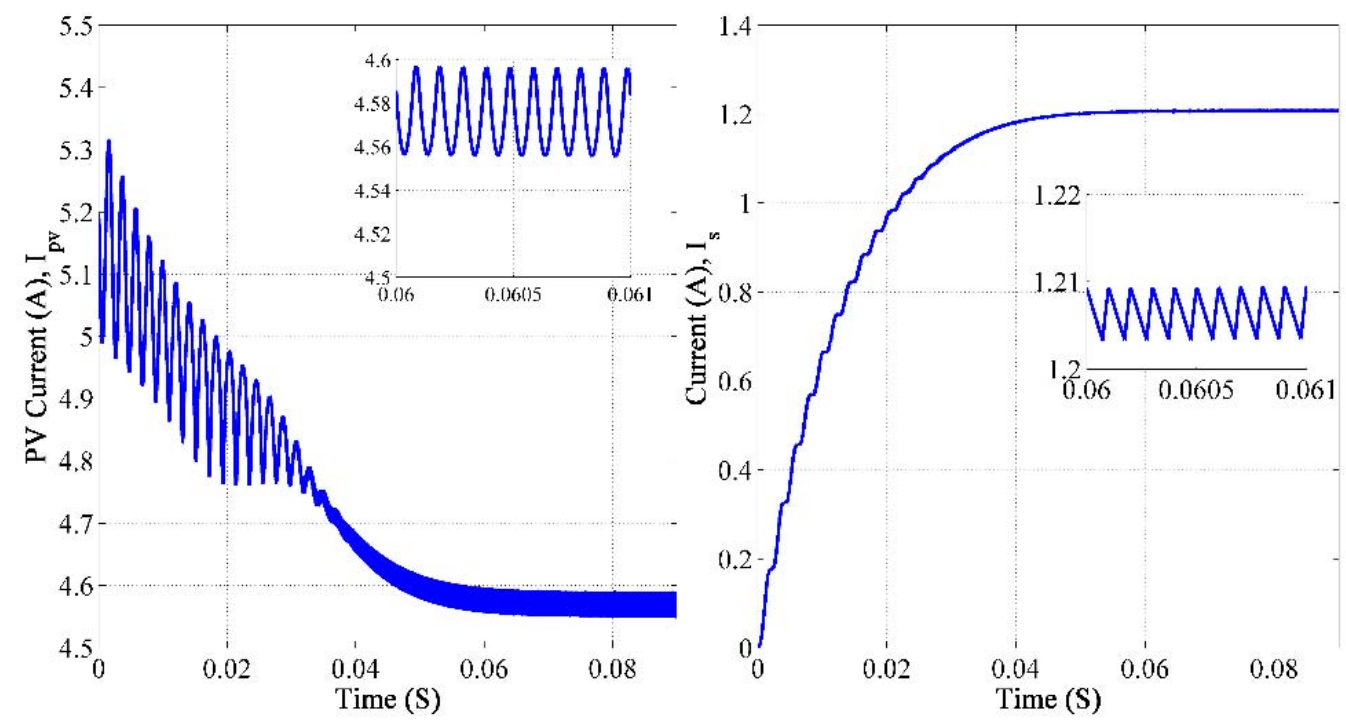

FIGURE 4. Input current $I_{P V}$ and output current $I_{S}$ of the boost converter when $\alpha=0.7226, R_{c h}=50 \Omega$, irradiation $=1000 \mathrm{~W} / \mathrm{m} 2$ at ambient temperature.
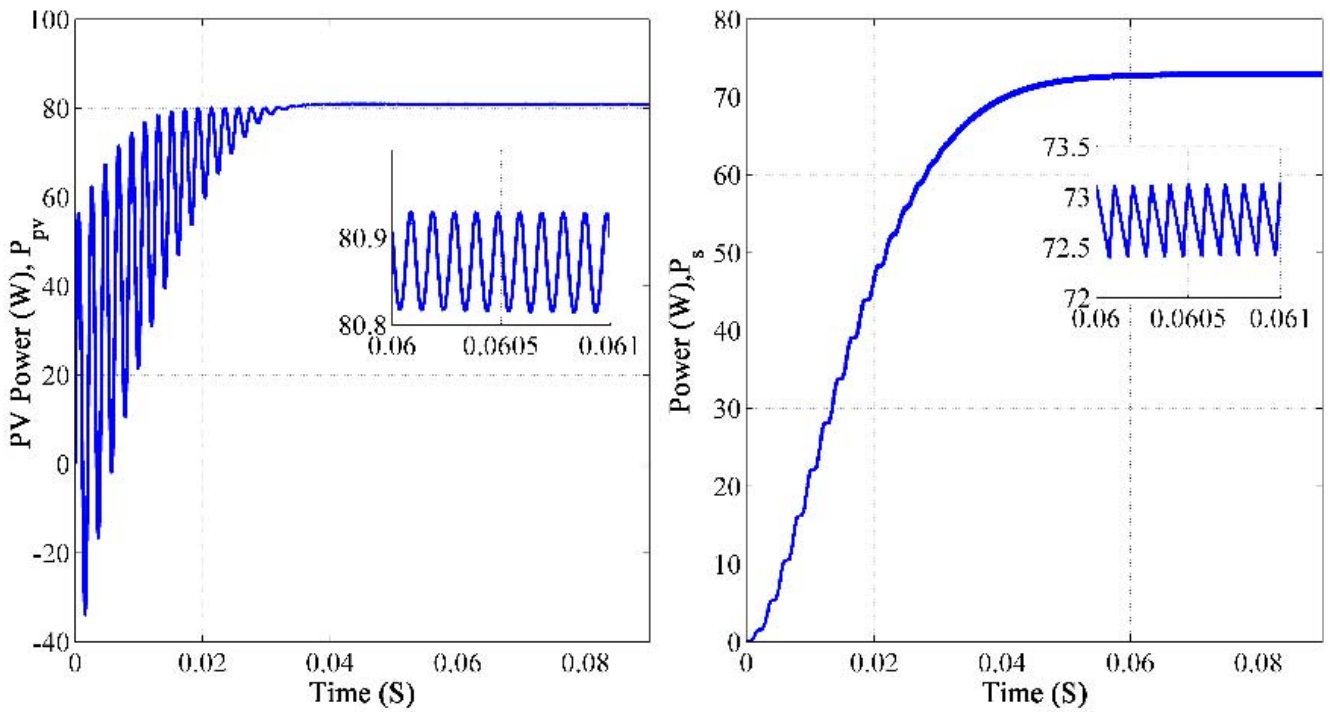

FIGURE 5. Input power $P_{P V}$ and output power $P_{S}$ of the boost converter when $\alpha=0.7226, R_{c h}=50 \Omega$, irradiation $=1000$ $\mathrm{W} / \mathrm{m} 2$ at ambient temperature.

From the plots in Figs. 3 to 5, one can remark that the MPP is successfully reached thanks to the MPP algorithm. The difference of power values equal to $7 \mathrm{~W}$ between the output power $\mathrm{P}_{\mathrm{s}}$ and the input power $\mathrm{P}_{\mathrm{pv}}$, is due to the boost converter losses (with simulation data corresponding to data indicated in the PVG ESM80S-12 characteristics and datasheet). 


\section{Influence of Load and Duty Cycle Variations}

We discuss in this section the influence of variations of both the load and the duty cycle of the converter on the boost electric responses (current, voltage, power) and on the PVG apparent resistance. Simulation results were reported in Figs. 6 to 9.
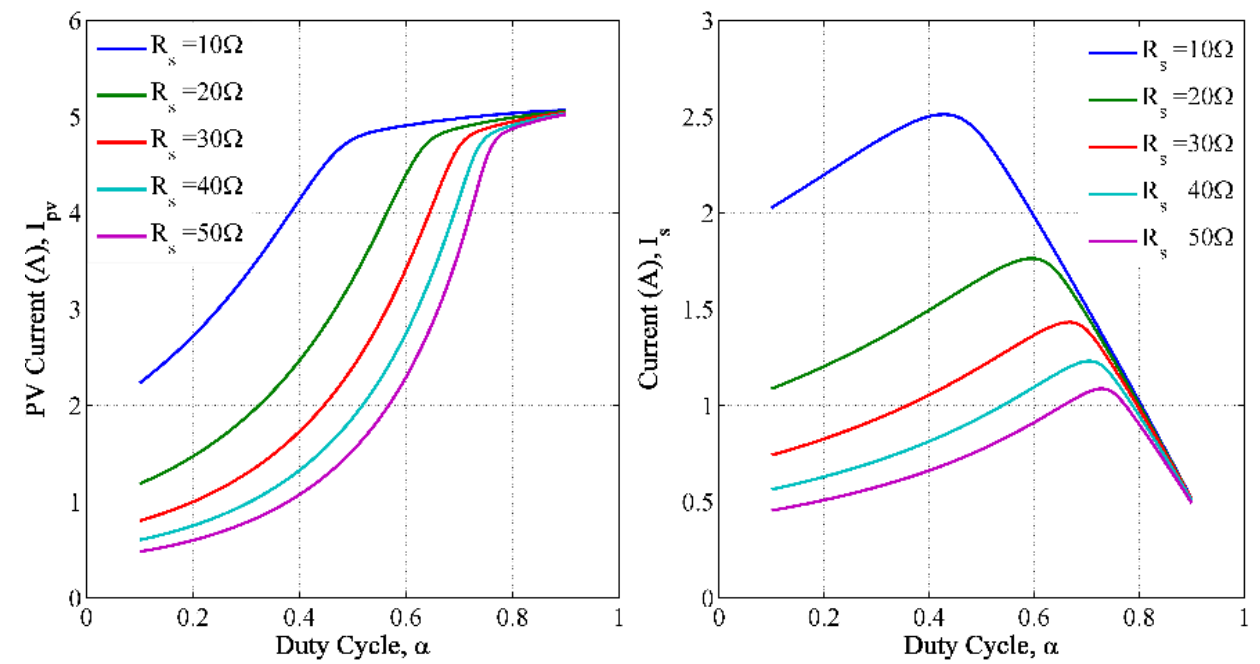

FIGURE 6. Input current $I_{p v}$ and output current $I_{s}$ of the boost according to load and duty cycle variations for an irradiation level equal to $1000 \mathrm{~W} / \mathrm{m}^{2}$ at room temperature.

Figure 6 shows that the current at the input, $\mathrm{I}_{\mathrm{PV}}$ of the boost converter passes through its threshold optimal value for a given duty cycle value $\alpha_{\mathrm{Th}}$. The threshold value of the duty cycle, $\boldsymbol{\alpha}_{\mathrm{Th}}$ increases with the series resistance, whereas, as attempted, the maximum delivered current decreases. In the studied range, $\alpha_{\mathrm{Th}}$ is equal to 0.5 for low load and go up to 0.8 for the maximum considered load, within a maximum IPV found around 5A. We notice that the effect of the adjustment of the duty cycle at $\boldsymbol{\alpha}_{\mathrm{Th}}$ is clearly observed at the output of the generator, also proving that the PVG is well adapted to the load. Consequently, the maximum output current does not exceed $2.5 \mathrm{~A}$ for low values of load being below $10 \Omega$.
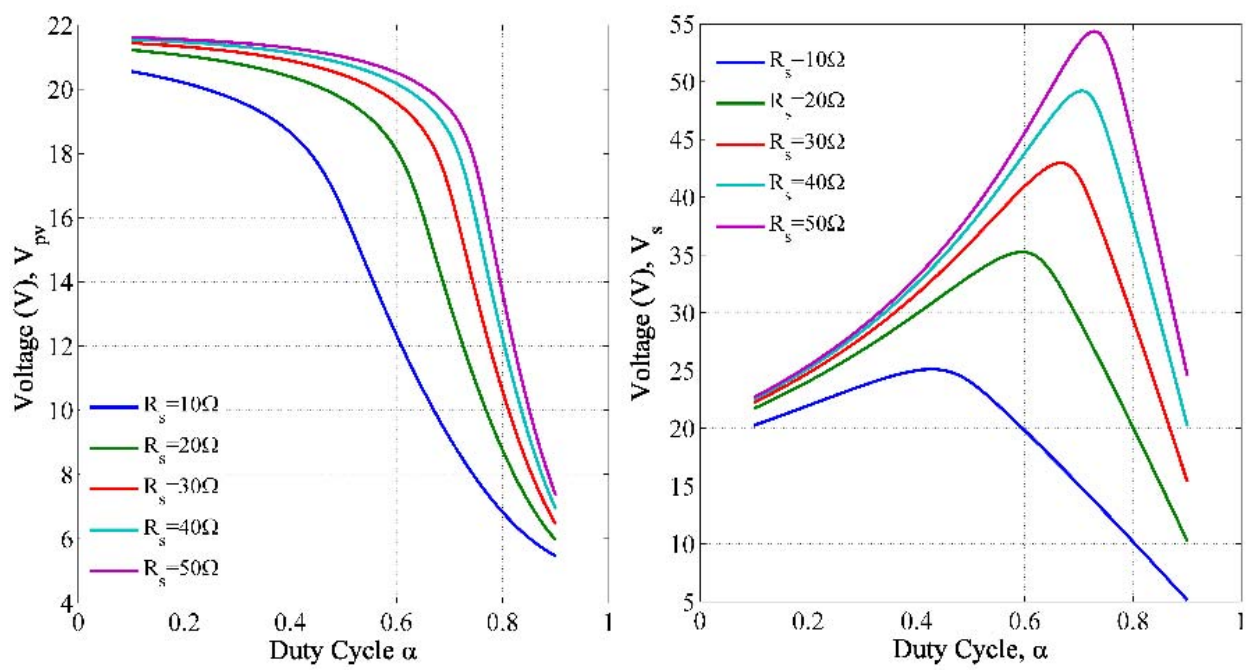

FIGURE 7. Input voltage $V_{p v}$ and output voltage $V_{s}$ of the boost according to load and duty cycle variations for an irradiation level equal to $1000 \mathrm{~W} / \mathrm{m}^{2}$ at room temperature. 
Fig. 7 shows voltage behaviors as function of the duty cycle. Of course, the duty cycle specific value $a_{\mathrm{Th}}$ corresponding to the maximum of the voltage is also clearly evidences as in Fig. 6 with electric currents behaviors. When the duty cycle increases, the voltage at the PVG input decreases and the output boost voltage increases and reaches its maximum value, for a given load, at $\alpha_{\mathrm{Th}}$ and above $\boldsymbol{\alpha}_{\mathrm{Th}}$, the output voltage, corresponding to the DC bus voltage, hugely decreases.

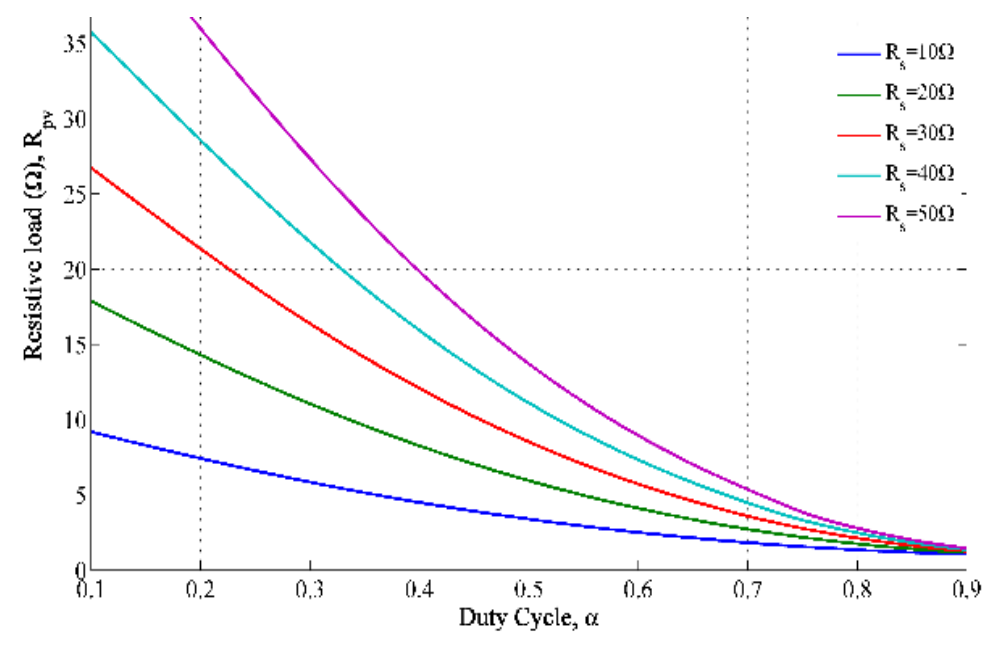

FIGURE 8. Output resistor $\mathrm{R}_{\mathrm{PV}}$ of the boost according to load and duty cycle variations for an irradiation level equal to 1000 $\mathrm{W} / \mathrm{m}^{2}$ at room temperature.

As shown in Fig. 8, the resistance $R_{p v}$ is very sensitive to duty cycle variations with a decrease described by Eq. 11 in $1 / \alpha^{2}$. In practice, due to the impossibility of variation of the duty cycle, these rapid changes of $R_{p v}$ limits the number of data points available for plotting the curves.
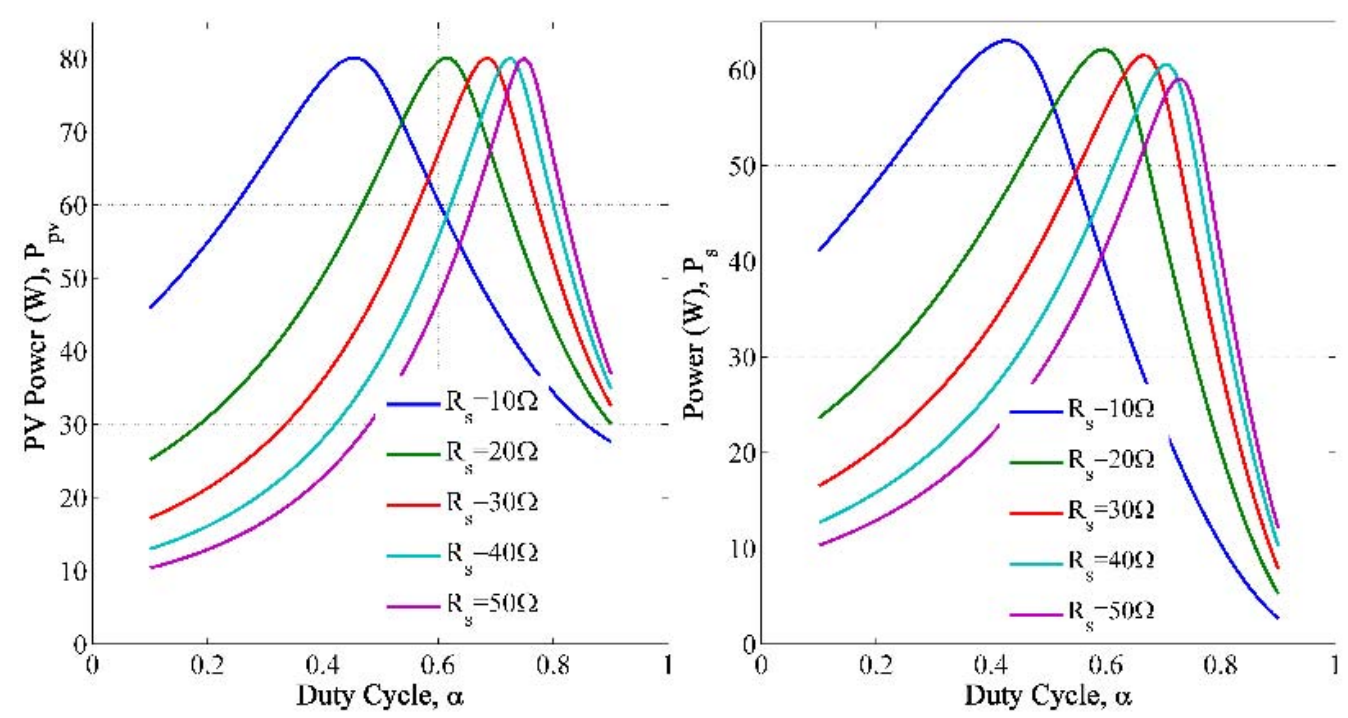

FIGURE 9. Input power $\mathrm{P}_{\mathrm{pv}}$ and output voltage $\mathrm{V}_{\mathrm{s}}$ of the boost according to load and duty cycle variations for an irradiation level equal to $1000 \mathrm{~W} / \mathrm{m}^{2}$ at room temperature. 
Finally, Fig. 9 clearly shows that for all the considered loads in the define range, the duty cycle moves up to $\boldsymbol{\alpha}_{\mathrm{Th}}$ in order to reach the MPP. For an input PV power equal to $80 \mathrm{~W}$, the maximum delivered power is found around $65 \mathrm{~W}$ but slightly decreases with the increase of the load resistor. Thus, for a given duty cycle, a decrease of the load resistance decreases the boost efficiency. Additionally, this observed behavior confirms the reliability of our chosen approach.

\section{CONCLUSION}

In this paper, a new analytical method is proposed for tracking the Maximum Power Point, MPP, of a distributed photovoltaic architecture system. A simple method based on the optimal PV apparent impedance, $\mathrm{R}_{\text {pvopt }}$ is used to calculate the optimum duty cycle in order to achieve rapidly the MPP. We have shown that with a simple Maximum Power Point Algorithm, high performances are obtained. In fact, all system responses follow practically their reference values according the MPPT strategy. Particularly, the output power at the load side is practically equal to maximum input power of the PVG according to its datasheet given in appendix. In addition, through this study, the upper and the lower limits of the load values are determined analytically in such a way that the boost operates in normal conditions. Finally, by considering the electric current, voltage, and power, especially the maximum power point, the boost performances are tested under simultaneous variation of the duty cycle and of the load in the operating range. Through simulation, it was shown that the efficiency of the boost is seriously degraded beyond $75 \%$ of the duty cycle and especially when the generator supplies low loads.

\section{REFERENCES}

1. T.M. Razykov, C.S. Ferekides, D. Morel, E. Stefanakos, H.S. Ullal, H.M. Upadhyaya, "Solar photovoltaic electricity: current status and future prospects", Solar Energy, 85(8), 1580-1608 (2011).

2. P. Petit, A. Zegaoui, J.P. Sawicki, M. Aillerie, J.P. Charles, "New architecture for high efficiency DC-DC converter dedicated to photovoltaic conversion”, Energy Procedia 6, 688-694 (2011).

3. A. Zegaoui, M. Aillerie, P. Petit, J.P. Sawicki, J.P. Charles, A.W. Belarbi, "Dynamic behaviour of PV generator trackers under irradiation and temperature changes", Solar Energy, 85(11), 2953-2964 (2011).

4. H.S. Bae, J.H. Park, B.H. Cho, G.J. Yu, "New MPPT control strategy for two-stage grid-connected photovoltaic power conditioning system", J. of Power Electron., 7(2), 174-180 (2007).

5. J.H.R. Enslin, M.S. Wolf, D.B. Snyman, W. Swiegers, "Integrated photovoltaic maximum power point tracking converter", IEEE Trans. Indust. Electron., 44(6), 769-773 (1997).

6. T. Esram, P.L. Chapman, "Comparison of photovoltaic array maximum power point tracking techniques", IEEE Trans. Energy Conver., 22(2), 439-449 (2007).

7. S. Jain, V. Agarwal, "Comparison of the performance of maximum power point tracking schemes applied to single-stage grid-connected photovoltaic systems”,IEEE Trans. Electron. Power Appl., 1(5),753-762 (2007).

8. F. Liu, Y. Kang, Y. Zhang, S. Duan, "Comparison of P\&O and hill climbing MPPT methods for gridconnected PV converter", IEEE Conference on Industrial Electronics and Applications, Singapore, IEEE, 804807 (2008).

9. J.M. Carrasco, L.G. Franquelo, J.T. Bialasiewicz, E. Galvan, R.C.P. Guisado, M.A.M. Prats, J.I. Leon, N. Moreno-Alfonso, "Power electronic systems for the grid integration of renewable energy sources", IEEE Trans. Ind. Electron., 53(4), 1002-1016 (2006).

10. H.S. Kim, J.H. Kim, B.D. Min, D.W. Yoo, H.J. Kim, “A highly efficient PV system using a series connection of DC-DC converter output with a photovoltaic panel”, Renewable Energy, 34(11), 2432-2436 (2009).

11. M. Sahoo, K.S. Kumar, "High gain step up DC-DC converter for DC micro-grid application", IEEE International conference on Information and Automation for Sustainability, Colombo (2014).

12. M.A. Farahat, H.M.B. Metwally, M.A. Abd-Elfatah, "Optimal choice and design of different topologies of DC-DC converter used in PV systems, at different climatic conditions in Egypt”, Renewable Energy, 43, 393402 (2012).

13. W. Qian, D. Cao, J.G. Cintron-Rivera, M. Gebben, D. Wey, F.Z. Peng, "A switched-capacitor DC-DC converter with high voltage gain and reduced component rating and count", IEEE Trans. Ind. Electron., 48(4), 1397-1406 (2012).

14. H. Chung, Y.K. Mok, "Development of a switched-capacitor DC/DC boost converter with continuous input current waveform”, IEEE Trans. Circuit Syst. I, 46(6), 756-759 (1999). 
15. A. Gandmkar, J.J. Seok, "Inductive-boost switched-capacitor DC/DC converter for maximum power point tracking photovoltaic systems", IEEE Energy Conversion Congress and Exposition (ECCE), Pittsburgh, IEEE, 5296-5303 (2014).

16. R.J. Wai, C.Y. Lin, R.Y. Duan, Y.R. Chang, "High-efficiency power conversion system for kilowatt-level stand-alone generation unit with low input voltage", IEEE Trans. Ind. Electron., 55(10), 3702-3714 (2008).

17. F.L. Luo, "Six self-lift DC-DC converters, voltage lift technique", IEEE Trans. Ind.Electron., 48(6), 12681272 (2001).

18. F.L. Luo, H. Ye, Advanced DC/DC Converters, CRC Press, Boca Raton, Florida, USA (2004).

19. T. Nouri, E. Babaei, S. Hossein, "A generalized ultra step-up DC-DC converter for high voltage applications with design considerations”, Electr. Power Syst. Res., 105, 71-84 (2013).

20. K.I. Hwu, Y.T. Yau, "Inductor-coupled KY boost converter”, Electron. Lett., 46(24), 1624-1626 (2010).

21. X. Hu, C. Gong, "A high voltage gain DC-DC converter integrating coupled-inductor and diode-capacitor techniques”, IEEE Trans. Power Electron., 29(2), 789-800 (2014).

22. Z.H. Shi, K.W.E. Cheng, S.L. Ho, "Static performance and parasitic analysis of tapped-inductor converters", IET Power Electron., 7(2), 366-375 (2014).

23. D.A. Grant, Y. Darroman, J. Suter, "Synthesis of tapped-inductor switched-mode converters", IEEE Trans. Power Electron., 22, 1964-1969 (2007).

24. D.A. Grant, Y. Darroman, "Extending the tapped-inductor DC-to-DC converter family", Electron. Lett., 37(3), 145-146 (2001).

25. K.W.E. Cheng, "Tapped inductor for switched-mode power converters", Int.Conf. on Power Electronics Systems and Applications,Hong Kong, 14-20 (2006).

26. H. Allouache, A. Zegaoui, G. Bachir, A. Djahbar, A. Dellali, M. Aillerie, "Limits of DC Bus Behavior on Photovoltaic Systems in Distributed Architecture", J. of Electrical Engineering, 17(1), 435-439 (2017). 